\title{
Comparison of two yttrium-90 regimens in inflammatory and osteoarthropathies
}

\author{
R Will, B Laing, J Edelman, F Lovegrove, I Surveyor
}

\begin{abstract}
Two yttrium-90 $\left({ }^{90} \mathrm{Y}\right)$ radiosynovectomy procedures were compared. One procedure, performed at the Royal Perth Rehabilitation Hospital (RPRH) required a shorter immobilisation time than that performed at the Sir Charles Gardiner Hospital (SCGH). There were no significant differences in outcome between the two procedures for the groups with inflammatory and osteoarthropathy. Thirty two patients (45 joints) with inflammatory arthropathy were treated ( 25 with rheumatoid arthritis, three with psoriatic arthritis, two with ankylosing spondylitis, and two with unspecified inflammatory arthropathy) and $\mathbf{4 0}$ patients (58 joints) with osteoarthropathy. A separate assessment of local lymph node spread in patients treated by the RPRH showed a minor spread of ${ }^{90} \mathrm{Y}$ in one of 37 joints assessed. A marked improvement in the patient evaluation scores in the inflammatory arthropathy group at three months persisted at 12 months. Good lasting responses were more common in patients with inflammatory arthropathy with a normal joint or early radiological disease. A marked improvement in the pain and evaluation scores occurred at three months in the group with osteoarthropathy but had disappeared by six months after treatment.
\end{abstract}

Radiation synovectomy has been widely used to treat patients with persistently inflamed joints since the 1963 report of Ansell et al. ${ }^{1}$ However, there continues to be a lack of consensus of the efficacy of this procedure in patients with inflammatory arthropathies ${ }^{2} 3$ and very little data on its relevance to patients with osteoarthropathies. ${ }^{4}$ There have been few reports on the treatment of joints other than the knee, although with current imaging facilities and the use of iodinated water soluble contrast agents needles can be accurately placed in the joint space and radioisotopes instilled. The injection of larger joints such as the hip and shoulder are preferred, but smaller joints (elbows and ankles) can also be treated with this procedure. Immobilisation of the joint following the injection of yttrium$90\left({ }^{90} \mathrm{Y}\right)$ is now considered to be essential to reduce the spread of the isotope to regional lymph nodes and the liver. ${ }^{5} 6$ Immobilisation of the joint with a long leg plaster cylinder applied prior to the procedure with a window cut for access adequately immobilises the joint but is time consuming to fit and cumbersome to wear. ${ }^{7}$ Nevertheless, it allows the procedure to be performed on outpatients. Strapping of the joint with a Robert Jones bandage produces inadequate immobilisation and local dissemination of the isotope. ${ }^{7}$ There has been little evaluation of different immobilisation regimens on local isotope spread or patient outcome. We undertook a study of ${ }^{90} \mathrm{Y}$ synovectomy in patients with inflammatory arthropathy or osteoarthropathy treated at two hospitals, the Royal Perth Rehabilitation Hospital (RPRH) and the Sir Charles Gardiner Hospital (SCGH), with different immobilising regimens over an 18 month period. Patients were assessed prior to the procedure and up to 12 months following the injection to evaluate outcome. Scanning of the joint and regional lymph nodes was undertaken in patients having less rigid immmobilisation to assess the spread of the radioisotope.

\section{Patients and methods}

Patients for whom conservative treatment for pain or swelling of a joint was unsuccessful and who were admitted to the RPRH or the SCGH for an intra-articular ${ }^{90} \mathrm{Y}$ injection were entered into the study between June 1986 and June 1987. The knee was the joint most often injected, but other joints were also evaluated. Patients were reviewed less than two weeks before the injection and were reassessed 6,12 , 26 , and 52 weeks following the procedure.

\section{INJECTION PROCEDURES}

The RPRH patients were admitted on day 1 , the joint was aspirated and $1-5 \mathrm{ml}$ of pantopaque were instilled to assess the needle position. If this was satisfactory $20 \mathrm{mg}$ triamcinolone acetonide and ${ }^{90} \mathrm{Y}$ were injected. The knee joint was immobilised using a semi-rigid Richard's splint and the patient was confined to bed for 48 hours. Splinting of the hip was not possible. One patient had an elbow injected; this was immobilised by strapping the patient's arm to the chest.

At the SCGH the patients were admitted on day 1 , the joints were aspirated and injected with $20 \mathrm{mg}$ triamcinolone acetonide and the knees were rested in a rigid Richard's splint. The upper limb joints were again immobilised by binding the patient's arm to his/her chest wall. The patients did not bear any weight on the joints but had access to bathroom facilities. On day 4 the joint was injected with ${ }^{40} \mathrm{Y}$ and remained immobilised for a further four days. The time spent in hospital was two and eight days for the RPRH and SCGH patients, respectively. 
DOSE OF YTTRIUM-90

There were some differences between the two hospitals in the dose of ${ }^{90} \mathrm{Y}$ given. The ${ }^{90} \mathrm{Y}$ doses for the knee, hip, and elbow at the RPRH were 200,120 , and $80 \mathrm{MBq}$, respectively, and at the SCGH were $185 \mathrm{MBq}$ for the knee and hip and $111 \mathrm{MBq}$ for the shoulder.

\section{PATIENT ASSESSMENT}

The clinical diagnosis, current drug treatment, reasons for the ${ }^{90} \mathrm{Y}$ synovectomy, the number of previous aspirations and intra-articular injections of steroids in the previous 12 months and the response to the last intra-articular injection of steroids were recorded at the initial assessment. A radiograph of the joint to be injected was reviewed if available. The patient recorded on an analogue scale $(0-100 \mathrm{~mm})$ the degree of pain in the joint. The duration of morning stiffness (minutes), the pain free walking distance (metres), and standing time (minutes) over the previous week were recorded at the first visit. The tenderness score (range $0-3$ ) of the joint to be injected was assessed by a clinical metrologist (BL) as described previously. ${ }^{8}$ At review the initial assessments were repeated and in addition the number of joint aspirations necessary since the ${ }^{90} \mathrm{Y}$ injection and the patient's evaluation of the joint (1=good, $2=$ same, 3 =worse) were recorded.

\section{RADIOLOGICAL ASSESSMENT}

Radiographic changes in the inflammatory arthropathy and osteoarthropathy groups were classified as normal or early if there was persisting joint space, or advanced if there was no residual joint space.

\section{GAMMA CAMERA SCANNING FOLLOWING}

\section{INJECTION OF YTTRIUM-90}

This was undertaken on the RPRH patients to assess the distribution of the isotope within the joint space and the extent of distribution outside the joint following the ${ }^{90} \mathrm{Y}$ injection. ${ }^{9}$ Yttrium90 (a pure beta $(\beta)$ emitter) was imaged using Bremsstrahlung radiation. This is 'scattered' radiation arising from the interaction of $\beta$ particles with the tissue. The joint was imaged 48 hours following the instillation of ${ }^{90} \mathrm{Y}$. The joint was positioned under a gamma camera and images of the appropriate joint were obtained in 10-15 minutes. The inguinal and axillary regions were also imaged.

\section{STATISTICAL METHODS}

Unpaired parametric data were compared using the $t$ test and paired parametric and nonparametric data with the paired $t$ test and the
Wilcoxon signed rank test, respectively. A binomial test was used to calculate an exact $p$ value when comparisons of patient evaluation scores were made. A patient evaluation score of 2 was assumed before the procedure. Statistical analyses were made using the OXSTAT program. ${ }^{10} \mathrm{~A} p$ value less than 0.05 was regarded as statistically significant.

\section{Results}

Seventy two patients (103 joints) were treated over a 12 month period at the two study hospitals and followed prospectively for 12 months following injection of ${ }^{90} \mathrm{Y}$. The mean age of the 19 patients with inflammatory arthropathy from the RPRH (nine men) was 54.3 years and the mean age of the 13 SCGH patients with inflammatory arthropathy (five men) was 58.9 years. There was an uneven distribution of patients with osteoarthropathy; seven patients (one man) were treated at the RPRH and 33 (11 men) at the SCGH. The mean ages of the patients with osteoarthropathy from the RPRH and SCGH were 74.6 and 70.3 years, respectively. A total of 45 inflammatory arthropathy and 58 osteoarthropathy joints were injected. Table 1 shows the distribution of joints injected at the two centres. The knee joint was the joint most often injected in the two patient categories. Seven hip joints were injected in the osteoarthropathy group. The inflammatory arthropathy group included 25 patients with rheumatoid arthritis, three with psoriatic arthritis, two with ankylosing spondylitis, and two with an unspecified inflammatory arthropathy. Before injection the mean (SD) joint tenderness score in the inflammatory arthropathy group was $0.66(0.62)$ and $1 \cdot 12(0.82)$ for the RPRH and SCGH patients, respectively. The baseline difference was not significant initially but became significant at six weeks, six months, and 12 months following the injection. This was most marked at 12 months $(t=2 \cdot 44 ; \mathrm{p}<0.05)$. The difference in the joint tenderness score between the two hospitals following the procedure is of questionable significance and can be accounted for by the difference in the baseline joint tenderness scores prior to the procedure. There was no significant difference in the pain score or patient evaluation score between the two hospitals in the inflammatory arthropathy or osteoarthropathy groups before or during the study. Owing to the similarities in the patient responses during the course of the study, patient data from the RPRH and SCGH were combined for the analysis of outcome (table 2).

The inflammatory arthropathy group included

Table 1 Categories of patients and joints

\begin{tabular}{|c|c|c|c|c|c|c|c|c|c|c|}
\hline & \multicolumn{5}{|c|}{ Inflammatory arthropathy } & \multicolumn{5}{|c|}{ Osteoarthropathy } \\
\hline & $\begin{array}{l}\text { No of patients } \\
\text { (\%) }\end{array}$ & Knee & Hip & Elbow & Shoulder & $\begin{array}{l}\text { Noof patients } \\
(\%)\end{array}$ & Knee & Hip & Elbow & Shoulder \\
\hline $\begin{array}{l}\text { SCGH } \\
\text { RPRH } \\
\text { Total } \\
\text { Men } \\
\text { Women }\end{array}$ & $\begin{array}{l}13(41) \\
19(59) \\
32(100) \\
14(44) \\
18(66)\end{array}$ & $\begin{array}{l}16 \\
26 \\
42\end{array}$ & $\begin{array}{l}\mathbf{0} \\
\mathbf{0} \\
\mathbf{0}\end{array}$ & $\begin{array}{l}0 \\
1 \\
1\end{array}$ & $\begin{array}{l}2 \\
0 \\
2\end{array}$ & $\begin{aligned} & 33(83) \\
& 7(17) \\
& 40(100) \\
& 12(30) \\
& 28 \\
& 28(70)\end{aligned}$ & $\begin{array}{r}38 \\
9 \\
47\end{array}$ & $\begin{array}{l}6 \\
1 \\
7\end{array}$ & $\begin{array}{l}\mathbf{0} \\
\mathbf{0} \\
\mathbf{0}\end{array}$ & $\begin{array}{l}4 \\
0 \\
4\end{array}$ \\
\hline
\end{tabular}

Total number of joints injected: inflammatory arthropathy $=45$, osteoarthropathy $=58$. Forty two patients had one joint injected, 29 two joints, and one three joints. Patients (joints) lost to follow up by 12 months: inflammatory arthropathy=four (10) (two patients deceased), osteoarthropathy=five (11) 
Table 2 Mean (SD) scores at 6, 12, 26, and 52 weeks following the ${ }^{9}$ Y/intra-articular steroid injection in patients with inflammatory arthropathy and osteoarthropathy. The results are the difference between the initial and follow up scores

\begin{tabular}{|c|c|c|c|c|c|c|c|c|}
\hline \multirow{2}{*}{$\begin{array}{l}\text { Post injection } \\
\text { assessment }\end{array}$} & \multicolumn{4}{|c|}{ Inflammatory arthropathy } & \multicolumn{4}{|c|}{ Osteoarthropathy } \\
\hline & $\begin{array}{l}\text { Six } \\
\text { weeks }\end{array}$ & $\begin{array}{l}\text { Three } \\
\text { months }\end{array}$ & $\begin{array}{l}\text { Six } \\
\text { months }\end{array}$ & $\begin{array}{l}12 \\
\text { months }\end{array}$ & $\begin{array}{l}\text { Six } \\
\text { weeks }\end{array}$ & $\begin{array}{l}\text { Three } \\
\text { months }\end{array}$ & $\begin{array}{l}\text { Six } \\
\text { months }\end{array}$ & $\begin{array}{l}12 \\
\text { months }\end{array}$ \\
\hline $\begin{array}{l}\text { Pain score }(0-100 \mathrm{~mm}) \\
t^{*} \\
\mathrm{p}\end{array}$ & $\begin{array}{l}20 \cdot 8(38 \cdot 7) \\
3 \cdot 48 \\
<0.01\end{array}$ & $\begin{array}{l}21 \cdot 2(33 \cdot 2) \\
3 \cdot 99 \\
<0 \cdot 001\end{array}$ & $\begin{array}{l}22 \cdot 8(38 \cdot 5) \\
3 \cdot 79 \\
<0.001\end{array}$ & $\begin{array}{l}10 \cdot 6(29 \cdot 9) \\
2 \cdot 12 \\
<0.05\end{array}$ & $\begin{array}{l}22 \cdot 6(29 \cdot 4) \\
5 \cdot 60 \\
<0 \cdot 001\end{array}$ & $\begin{array}{l}20 \cdot 6(27 \cdot 3) \\
5 \cdot 55 \\
<0 \cdot 001\end{array}$ & $\begin{array}{l}3 \cdot 6(30 \cdot 6) \\
0.84 \\
<0 \cdot 190\end{array}$ & $\begin{array}{l}7 \cdot 9(29 \cdot 6) \\
1.84 \\
<0.085\end{array}$ \\
\hline $\begin{array}{l}\text { Joint tenderness score } \\
(0-3) \\
\mathrm{z} \dagger \\
\mathrm{p}\end{array}$ & $\begin{array}{l}0.4(0 \cdot 8) \\
-2 \cdot 56 \\
0.011\end{array}$ & $\begin{array}{l}0.3(1 \cdot 1) \\
-1.92 \\
0.055\end{array}$ & $\begin{array}{l}0 \cdot 3(0 \cdot 8) \\
-2 \cdot 28 \\
0 \cdot 023\end{array}$ & $\begin{array}{l}0.6(0 \cdot 8) \\
-2.97 \\
0.003\end{array}$ & $\begin{array}{l}0.1(0 \cdot 8) \\
0.35 \\
0.725\end{array}$ & $\begin{array}{l}0 \cdot 2(0 \cdot 8) \\
-2 \cdot 04 \\
0 \cdot 042\end{array}$ & $\begin{array}{l}0 \cdot 1(1 \cdot 0) \\
-0.30 \\
0.42\end{array}$ & $\begin{array}{l}0.0(0 \cdot 8) \\
-0.17 \\
0.87\end{array}$ \\
\hline $\begin{array}{l}\text { Patient evaluation score } \\
(1-3) \\
\text { p } \ddagger\end{array}$ & $\begin{array}{l}1.4(0.7) \\
2.82 \times 10^{-5}\end{array}$ & $\begin{array}{l}1.3(0.5) \\
1.45 \times 10^{-8}\end{array}$ & $\begin{array}{l}1.3(0.6) \\
1.66 \times 10\end{array}$ & $\begin{array}{l}1.5(0.9) \\
6.76 \times 10+\end{array}$ & $\begin{array}{l}1.5(0.7) \\
2.87 \times 10^{7}\end{array}$ & $\begin{array}{l}1.6(0.9) \\
4.07 \times 10^{3}\end{array}$ & $\begin{array}{l}2 \cdot 0(0 \cdot 9) \\
0.15\end{array}$ & $\begin{array}{l}2 \cdot 0(0 \cdot 0) \\
0 \cdot 13\end{array}$ \\
\hline
\end{tabular}

${ }^{*}$ Paired $t$ test.

tz Score calculated using Wilcoxon signed rank test.

‡Exact $p$ value calculated using binomial test.

Table 3 Radiological joint assessment prior to injection of yttrium-90 and patient evaluation at 12 months for inflammatory arthropathy and osteoarthropathy joints

\begin{tabular}{|c|c|c|c|c|c|c|c|c|}
\hline \multirow[t]{2}{*}{ Patient evaluation } & \multicolumn{4}{|c|}{$\begin{array}{l}\text { Inflammatory arthropathy } \\
\text { radiological assessment }\end{array}$} & \multicolumn{4}{|c|}{$\begin{array}{l}\text { Osteoarthropathyt: } \\
\text { radiological assessment }\end{array}$} \\
\hline & Normal & Early & Advanced & Not done & Normal & Early & Advanced & Not done \\
\hline Good (1) & 7 & 8 & 5 & 7 & - & 8 & 12 & - \\
\hline No change (2) & - & - & 1 & - & - & 2 & 3 & 2 \\
\hline Worse (3) & - & 1 & 6 & 1 & - & 6 & 13 & 1 \\
\hline Lost to follow up & - & 4 & - & 4 & 1 & 3 & 3 & - \\
\hline Surgery & - & - & 1 & - & - & 1 & 2 & 1 \\
\hline
\end{tabular}

${ }^{*} \chi^{2}$ Normal and early $v$ advanced $=13 \cdot 70$; degrees of freedom $(\mathrm{df})=4 ; \mathrm{p}<0.01$.

$+\chi^{2}$ Normal and early $v$ advanced $=0.770 ; \mathrm{df}=4 ; \mathrm{p}>0.5$.

two patients who were not using a non-steroidal anti-inflammatory drug (NSAID), 22 who were using one such drug and eight who were using two such drugs at the time of the injection. A second line antirheumatic drug was being used by 27 of 32 patients with inflammatory arthropathy at the start of the study. The procedure was performed in the inflammatory arthropathy joints because of pain in eight, an effusion in seven, and pain and an effusion in 30 patients. In the previous 12 months less than two or more than three intra-articular steroidal injections had been performed in 30 and 15 joints, respectively. The response to the intra-articular steroid injection was rated as good in $34 \%$ of patients. Table 3 shows that radiographs were not available for review in 12 joints, were normal in seven joints, showed early changes in 13 joints, and advanced changes in 13 . One patient had surgery on both injected joints within 12 months of the ${ }^{90} \mathrm{Y}$ and intra-articular steroid injection.

The osteoarthropathy group included 10 patients who were not using NSAIDs, 27 who were using one NSAID, and three who were using two NSAIDs at the time of the procedure. The procedure was undertaken in all osteoarthropathy joints as a result of pain. In half the joints a significant effusion was also present. An intra-articular steroid injection had been performed less than two or more than three times in 45 and 13 joints, respectively, in the 12 months prior to the ${ }^{90} \mathrm{Y}$ injection and intraarticular steroid injection. Radiograph(s) obtained prior to the procedure were not available for assessment in four joints, were normal in one joint, and showed early or advanced changes in 20 and 33 joints, respectively. Four patients had surgery on the injected joint within 12 months of the ${ }^{90} \mathrm{Y}$ and an intraarticular steroid injection.
The patients with inflammatory arthropathy had a significant improvement in pain, joint tenderness, and overall patient evaluation score at most time points following the procedure (table 2). The overall evaluation of the procedure showed that at 12 months a good result occurred in 26 joints (74\%), a poor result in eight joints $(23 \%)$, and no change in one joint $(3 \%)$. Patients with a normal joint or early radiological disease had a better response to ${ }^{90} \mathrm{Y}$ than those with advanced radiological damage (table 3). The results for the osteoarthropathy group show a different profile (table 2). There was a marked improvement in pain at the six and 12 week assessments, but this had disappeared by later assessments. There was little change in the joint tenderness scores and the change in the patient evaluation scores was similar to the pain scores. The procedure in the osteoarthropathy group was rated as good for 20 joints $(43 \%)$, poor for 20 joints $(43 \%)$, and there was no change in seven joints $(14 \%)$ at 12 months. The radiographic damage at onset in the patients with osteoarthropathy did not influence the reports of a good or poor response at 12 months (table 3 ). The duration of morning stiffness, the pain free walking distance, and the standing time did not change significantly in either the inflammatory arthropathy or osteoarthropathy groups at any of the follow up assessments compared with the initial assessment. Gammacamera scanning of 37 joints injected at the RPRH showed only minimal lymph node activity from one joint $(2 \cdot 7 \%)$.

\section{Discussion}

A beneficial response to the injection of ${ }^{90} \mathrm{Y}$ and intra-articular steroid injection in the inflammatory arthropathy group in this open study confirms the impression of other studies. ${ }^{11-13}$ This procedure has also been shown 
to be of benefit in calcium pyrophosphate arthropathy ${ }^{14}$ and villonodular synovitis. ${ }^{15}$ Some patients in the inflammatory arthropathy group who had an initial limited response continued to improve by three and six months. This is indicated by the patient evaluation scores in table 2. This study cannot address whether some of the improvement observed in the inflammatory arthropathy group was due to the enforced bed rest and splinting in association with the intra-articular steroid injection. The previous poor responses to intra-articular steroid injection suggest that some of the improvement plus the delay in the improvement is likely to be explained by the ${ }^{90} \mathrm{Y}$. The results of this study also suggest that although some patients receiving intra-articular steroid injection and with significant cartilage loss may respond to ${ }^{90} \mathrm{Y}$ and an intra-articular steroid injection, patients who have less cartilage loss have a better outcome. The difference in baseline tenderness scores between the two hospitals in the patients with inflammatory arthropathy satisfactorily explains the limited differences in joint tenderness during the study. Joint tenderness as assessed by a metrologist, particularly if cartilage damage is present, is a less useful parameter than the patient's self assessed pain score or evaluation of the procedure. The lack of a difference in these assessments between the two hospitals may not have been detected because of a type two error; alternatively the technique used at the RPRH may be just as effective as the more lengthy procedure adopted at the SCGH.

The procedure adopted at the RPRH resulted in a minimal spread of ${ }^{90} \mathrm{Y}$ to the local lymph nodes in $2.7 \%$ of the patients studied. Accordingly, semi-rigid splinting and bed rest seem to be adequate to prevent significant leakage of the radioisotope from the injected joint. Patients who are injected in an upper limb joint may be more likely to disperse the isotope because of the difficulties associated with the immobilisation of these joints. Assessments of chromosomal damage in lymphocytes where there has been minimal of isotope spread have shown only a limited degree of cytogenetic damage. ${ }^{16}$ There have also been considerable differences between laboratories in their assessment of the degree of cytogenetic damage occurring in lymphocytes. ${ }^{17}$ It is most unlikely that this degree of radioisotope spread in our patients would cause an appreciable increase in cancer risk, and in spite of this radioisotope having been used for over $\mathbf{3 0}$ years there have been no reports of malignancies directly attributable to its use. ${ }^{16}$

There did not appear to be any difference in outcome between the two treated groups with osteoarthropathy. Once again this may not have been detected because of the small number of patients treated at the RPRH. Twenty of the patients with osteoarthropathy rated the joint as good at 12 months. Some of this improvement may be explained by the effect of the intraarticular steroid injection, bed rest, and splintage of the joint. It is also known from prospective studies of patients with osteoarthropathy of the knee (the largest group in this study) that a sizeable number of these patients may spon- taneously improve over a 12 month period. ${ }^{17}$ Spooren $e t a l^{4}$ also noted that a number of their patients seemed to respond to ${ }^{90} \mathrm{Y}$. There do not appear to be any clinical characteristics which identify responders with osteoarthropathy from non-responders (some patients with advanced radiological changes also responded). This patient group now warrants further assessment with an untreated control group to assess the reasons for the clinical response, identify patients who may respond, and finally to ensure that this procedure does not result in accelerated cartilage breakdown. This procedure does appear to benefit some patients with osteoarthropathy and may give a more prolonged response than intra-articular steroid injection. It may give a longer period of symptomatic relief prior to consideration of total joint replacement.

The continuing evidence is compelling that ${ }^{90} \mathrm{Y}$ has an established place in the management of persistent inflammatory synovitis of the knee. This study suggests that a short time of immobilisation after ${ }^{90} \mathrm{Y}$ injection is adequate to ensure a good prolonged improvement in joint symptoms. Further studies are required to define its role in synovitis of other joints, the osteoarthritic joint, and the benefits or side effects of repeated injections.

1 Ansell B M Crook A Malard J R Evaluation of intraarticular colloidal gold ${ }^{198} \mathrm{Au}$ in the treatment of persistent knee effusions. Ann Rheum Dis 1963; 22: 435-9.

2 knee effusions. Ann Rheum Dis 1963; 22: 435-9. I Rheumatol 1982; 9: 165-8.

3 Arthritis and Rheumatism Council Multicentre RadioArthritis and Rheumatism Council Multicentre Radio-
synoviorthesis Trial Group. Intra-articular radioactive yttrium and triamcinolone hexacetonide: an inconclusive trial. Ann Rheum Dis 1984; 43: 620-3.

4 Spooren P F M J, Rasker J J, Arens R P J H. Synovectomy of the knee with ${ }^{90} \mathrm{Y}$. Eur $\mathcal{f}$ Nucl Med 1985; 10: 441-5.

5 Gumpel J M, Williams E D, Glass H I. Use of yttrium 90 in persistent synovitis of the knee. I. Retention in the knee and spread in the body after injection. Ann Rheum Dis 1973 32: 223-7.

6 de la Chappelle A, Oka M, Rekonen A, et al. Chromosoma damage after intra-articular injections of radioactive yttrium. Effect of mobilization on biological dose. Ann Rheum Dis 1972; 31: 508-22.

7 Williams P L, Crawley J C W, Freeman A M, Lloyd D C Gumpel J M. Feasibility of outpatient management after intra-articular yttrium-90: a comparison of two regimens $B M F$ 1981; 282: 13-4.

8 Ritchie D A, Boyle J A, McInnes J M, et al. Clinical studies with an articular index for the assessment of joint tenderness in patients with rheumatoid arthritis. Qf Med 1968; 37 393-406.

9 Mullan B P, Surveyor I. Imaging yttrium-90 synovectomy studies. Australas Radiol 1989; 33: 379-81.

10 Oxstat V. The scientific and statistical data analysis system Oxford statistics, 1983-85.

11 Boerbooms AmTh, Buijs W C. A M, Danen M, van de Putte L B A, Vandenbrovoke J P. Radiosynovectomy in chronic synovitis of the knee joint in patients with rheumatoid arthritis. Eur $\mathcal{F}$ Nucl Med 1985; 10: 446-9.

12 Sledge C B, Atcher R W, Shortkroff S, Anderson R J Bloomer $W D$, Hurson B J. Intra-articular radiation synovectomy. Clin Orthop 1984; 182: 37-40.

13 Menkes C J, Aignan M, Galmiche B. Le traitment des rheumatismes par les synoviotheses choix des malades, choix des articulations, modalites pratiques, resultats, indications, contrein A Rheumatologie 1972; 2 (suppl 1): 61-6.

14 Doherty M, Dieppe P. Effect of intra-articular yttrium-90 on chronic pyrophosphate arthropathy of the knee. Lancet 1981 ; chronic pyr.

15 O'Sullivan M M, Yates D B, Prichard M H. Yttrium 90 synovectomy - a new treatment for pigmented villonuclear synovectomy-a new treatment for pigm
synovitis. Br $\mathcal{F}$ Rheumatol $1987 ; 26: 71-2$.

16 Doyle D V, Glass J S, Gow P J, Daker M, Grahame R. A clinica and prospective chromosomal study of yttrium-90 synoand prospective chromosomal study of yttrium
vectomy. Rheumatol Rehabil 1977; 16: 217-22.

17 Stevenson A C, Bedford J, Dolphin G W. Cytogenetic and scanning study of patients receiving intra-articular injections of gold-198 and yttrium-90. Ann R heum Dis 1973;32:112-23.

18 McCrae F, Palmer M, Shouls J, Watt I, Dieppe P. Bone scintigraphy predicts changes in X-rays of osteoarthritis of the knee. Br F Rheumatol 1990; 29 (suppl 2): 54. 